\title{
Interaction of Brassicaceous Seed Meal and Apple Rootstock on Recovery of Pythium spp. and Pratylenchus penetrans from Roots Grown in Replant Soils
}

\author{
Mark Mazzola, USDA Agricultural Research Service, Tree Fruit Research Laboratory, 1104 N. Western Avenue, \\ Wenatchee, WA 98801; Jack Brown, Department of Plant, Soil and Entomological Sciences, University of Idaho, \\ Moscow 83844-2339; Xiaowen Zhao, Washington State University, 1100 N. Western Avenue, Wenatchee 98801; \\ Antonio D. Izzo, USDA Agricultural Research Service, Tree Fruit Research Laboratory, 1104 N. Western Avenue, \\ Wenatchee, WA 98801; and Gennaro Fazio, USDA Agricultural Research Service, 630 W. North St., Hedrick Hall, \\ Geneva, NY 14456
}

\begin{abstract}
Mazzola, M., Brown, J., Zhao, X., Izzo, A. D., and Fazio, G. 2009. Interaction of brassicaceous seed meal and apple rootstock on recovery of Pythium spp. and Pratylenchus penetrans from roots grown in replant soils. Plant Dis. 93:51-57.

Pythium spp. and Pratylenchus penetrans are significant components of the diverse pathogen complex that incites apple replant disease in Washington State. The structure of the Pythium population differs among orchard soils but is composed of multiple pathogenic species. Studies were conducted to determine the effect of brassicaceous seed meals and apple rootstock on the activity and composition of these pathogen populations. Brassicaceous seed meals differed in capacity to suppress Pythium numbers and apple root infection, as well as differentially transformed composition of the population recovered from apple roots. Brassica juncea seed meal (SM) was the sole seed meal examined to suppress Pythium numbers and root infection; however, a persisting population was always detected in which Pythium irregulare existed as the dominant or co-dominant species. In general, the Geneva series rootstocks were less susceptible to root infection by native populations of Pythium, whereas M26, MM106, and MM111 were highly susceptible. Apple rootstocks from the Geneva series consistently supported lower populations of $P$. penetrans than did Malling or Malling-Merton rootstocks. B. juncea SM was superior to Brassica napus SM or Sinapis alba SM in suppressing lesion nematode populations. Significant rootstock $\times$ seed meal interaction was detected, and nematode suppression in response to B. napus or S. alba SM was only observed when used in concert with a tolerant rootstock, while $B$. juncea SM suppressed lesion nematode root populations irrespective of rootstock. These findings demonstrate that utilization of brassicaceous seed meal amendments for replant disease suppression must employ an appropriate rootstock in order to achieve optimal disease control.
\end{abstract}

Replant disease of apple is a biological syndrome that negatively impacts growth and development of young trees when established on sites previously planted to the same or closely related tree species (31). Tree performance in terms of vegetative growth and fruit yield typically improves substantially in response to preplant soil fumigation of such sites $(9,15,22)$. However, reports exist documenting a similar phenomenon, which based upon the absence of a tree growth response in fumigated soil is likely the result of abiotic

Corresponding author: M. Mazzola

E-mail: mark.mazzola@ars.usda.gov

Current address of A. D. Izzo: Department of Biology, Elon University, Elon, NC 27244.

Accepted for publication 19 September 2008.

doi:10.1094/PDIS-93-1-0051

This article is in the public domain and not copyrightable. It may be freely reprinted with customary crediting of the source. The American Phytopathological Society, 2009. rather than biotic forces and has been termed replant problem (25) or disorder (34). Apple replant disease is incited by a microbial complex that can vary among orchard sites (31), but which in Washington State consistently has been shown to be composed of a group of pathogens belonging to the genera Cylindrocarpon, Phytophthora, Pratylenchus, Pythium, and Rhizoctonia $(17,22)$. Elucidation of the causal pathogen complex has enabled formulation and evaluation of biologically sustainable measures as an alternative to preplant soil fumigation for the control of apple replant disease. Brassica napus seed meal (SM) applied as a preplant soil amendment when used in concert with a postplant mefenoxam drench was as effective as preplant soil fumigation in promoting growth and yield of apple on sites where lesion nematode, Pratylenchus penetrans, was not a significant component of the pathogen complex (22).

Resistant plant material can be an effective component of integrated pest management programs. The use of clonal sizecontrolling rootstocks is customary in commercial apple production systems, and the genetic diversity within Malus provides an opportunity to exploit host resistance as a means to control various pest and disease problems in apple. With the exception of Phytophthora spp. $(5,6,33)$, there has been little attention given to the relative sensitivity of apple rootstocks to individual soilborne pathogens. Differences in relative growth of apple rootstocks in replant orchard soils has been documented, but there is little information as to whether this was the result of differential tolerance to specific soilborne pathogens (27). Isutsa and Merwin (12) evaluated relative tolerance of rootstocks to apple replant disease and suggested that sources of genetic tolerance exist in Malus germplasm collections that could be useful for development of rootstocks for control of replant pathogens. They also noted that differences in relative reproduction of $P$. penetrans on clonal rootstock accessions were detected (12). Although Pythium and Rhizoctonia were isolated from root systems (12), the failure to identify these organisms to species, and the presence of numerous nonpathogenic and even growth-promoting members of these genera in orchard soils $(16,19)$, make conclusions concerning rootstock tolerance or resistance uncertain.

Although $B$. napus SM amendment effectively controls specific elements of the pathogen complex (e.g., Rhizoctonia solani) that incites apple replant disease, its application stimulates populations of $P y$ thium, leading to increased apple root infection (7). Use of a postplant mefenoxam soil drench in concert with a preplant $B$. napus SM amendment effectively suppresses Pythium apple root infection (22); however, this practice is not compatible with organic production systems. Other brassicaceous seed meals have differential impacts on this oomycete community (20), but there is no information as to the relative effect of these materials on species composition of indigenous Pythium populations. This information is of significance due to the considerable diversity in virulence of individual Pythium species toward apple (19).

This study was undertaken to examine the relative tolerance of apple rootstocks to 
indigenous populations of Pythium spp. and $P$. penetrans, and to determine whether brassicaceous seed meals differed in the capacity to suppress populations of these parasites or differentially altered composition of native Pythium communities.

\section{MATERIALS AND METHODS}

Orchard soils. Soils utilized in these studies were collected from the Wenatchee Valley College Research and Demonstration (WVC) orchard, East Wenatchee, WA; and a commercial (GC) orchard, Manson, WA. Characteristics of these soils were previously described $(17,18,21)$. Soil $\mathrm{pH}$ ranged from 6.9 (WVC) to 7.0 (GC) (Cascade Analytical, Wenatchee, WA). Disease development at the WVC orchard has been attributed to the activity of a fungal complex; whereas at the GC orchard, the lesion nematode, $P$. penetrans, contributed to growth suppression in concert with the same fungal complex (17). Soil was collected from the root zone of established trees at each site in March 2004 (GC, WVC), October 2004 (GC), and October 2005 (GC), as previously described (21).

Seed meals. Seed meals used in these studies were obtained from B. napus cv. Dwarf Essex (Montana Specialty Mills, Great Falls, MT), Brassica juncea cv. Pacific Gold (4), and Sinapis alba cv. IdaGold (3). Seed meals varied in glucosinolate profile and content. B. napus SM

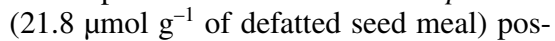
sessed the lowest content, of which 2hydroxy-3-butenyl and 4-pentenyl were the dominant glucosinolates. S. alba SM and B. juncea SM both possessed higher glucosinolate levels, 244 and $303 \mu \mathrm{mol} \mathrm{g}{ }^{-1}$ of defatted seed meal, respectively. 2Propenyl (allyl) composed $>99 \%$ of the glucosinolate contained in B. juncea SM, whereas $S$. alba SM contained $>95 \% p$ hydroxylbenzyl glucosinolate. Mineral contents for seed meals were as follows: nitrogen, 5.57 to $6.84 \%$; phosphorous, 1.21 to $1.39 \%$; potassium, 1.11 to $1.50 \%$; and sulfur, 0.86 to $1.59 \%$ (Soiltest Farm Consultants, Inc., Moses Lake, WA).

Plant material. Geneva series rootstocks (G11, G16, G30) were obtained from the U.S. Department of Agriculture Agricultural Research Service Plant Germplasm Repository Unit, Geneva, NY. Budagovsky 9 (Bud9), Malling (M) 7, M9Nic29, M9-Pajam2, M26, Malling-Merton (MM) 106, MM111, and Seedling rootstocks were obtained from Willow Drive Nursery, Ephrata, WA.

Soil treatment and plant assays. Irregularly shaped brittle flakes of the individual seed meals were ground in a blender to pass through a $1 \mathrm{~mm}^{2}$ metal mesh screen before incorporating into orchard soil at a rate of $0.5 \%(\mathrm{vol} / \mathrm{vol})$ with thorough mixing. Soils were decanted into 3.8 -liter pots and incubated on a greenhouse bench for 8 weeks at $22 \pm 3^{\circ} \mathrm{C}$ to permit development of specific microbial communities previously shown to suppress specific fungal pathogens resident to these orchard soils $(7,20)$. All treatments remained exposed to the ambient air, with the exception that two experiments conducted in GC soil possessed an additional treatment consisting of B. juncea SM amended soil that was sealed in polyethylene bags in order to more effectively contain volatile allylisothiocyanate (AITC) produced in response to this amendment (20). As AITC generation and emission from soils is completed within $24 \mathrm{~h}$ of amendment (20), soils were removed from bags after $48 \mathrm{~h}$ incubation.

At completion of the 8-week incubation period, one apple rootstock was planted per pot with four pots of each rootstock per treatment. Plants were arranged in a completely randomized design on the greenhouse bench. To compensate for the $\mathrm{N}$ inputs associated with seed meal treatments, $0.25 \mathrm{~g}$ of a $46-0-0$ fertilizer was applied in $150 \mathrm{ml}$ of water to each tree grown in the nontreated control soil treatments. Plants were watered at 3-day intervals, grown with a $16-\mathrm{h}$ photoperiod, and harvested after 6 months.

At harvest, a composite 5-g soil sample was collected, trees were removed from individual pots, and root systems were washed under tap water to remove adhering soil. Roots were excised from tree shoots and brought to the laboratory for determination of root infestation by $P$. penetrans and infection by Pythium.

Assessment of Pratylenchus and Pythium spp. populations. For determination of $P$. penetrans populations, a $0.5-\mathrm{g}$ subsample was excised from each tree root system and individual samples were placed into $125-\mathrm{ml}$ flasks containing $80 \mathrm{ml}$ of sterile distilled water. Flasks were placed on a reciprocal shaker and incubated at $150 \mathrm{rpm}$ for 7 days. Nematodes were collected by passing the suspension twice through a 350-mesh sieve and backwashing into a counting dish, and $P$. penetrans were counted using a light microscope $(\times 40)$.

Pythium soil populations were determined immediately prior to planting and at harvest. A 5-g soil sample was collected from each pot and resuspended in $25 \mathrm{ml}$ of sterile distilled $\mathrm{H}_{2} \mathrm{O}$, vortexed for $90 \mathrm{~s}$, and serial dilutions of the suspension were plated onto a Pythium semiselective medium (PSSM; 21). Infection of apple roots by Pythium was determined by randomly excising 20 root segments, 0.5 to $1.0 \mathrm{~cm}$ in length, from each tree and plating segments onto PSSM. Plates were incubated at room temperature and examined after 24 and $48 \mathrm{~h}$ to determine relative root infection and estimate soil populations of $P y$ thium spp.

For the experiment conducted in WVC soil and experiments 1 and 2 conducted in GC soil, species composition of the $P y$ thium spp. population recovered from ap- ple roots was determined. Hyphal growth typical of Pythium emerging from root segments plated on PSSM was excised and transferred to fresh PSSM, with a maximum of four isolates randomly selected per individual plant. This protocol resulted in the examination of 400 to 500 Pythium isolates in each experiment. Pythium isolates were incubated at room temperature for $48 \mathrm{~h}$, at which time three $0.4-\mathrm{cm}$ diameter plugs were excised from the growing margin of individual cultures, transferred to $5 \mathrm{ml}$ of $1 / 5$ th-strength potato dextrose broth (Becton, Dickinson, \& Company, Sparks, MD), and incubated for 4 to 7 days on a rotating platform (150 rpm) at ambient laboratory conditions. DNA was extracted from Pythium sp. mycelium using a MoBIO Ultraclean Microbial DNA isolation kit (MO BIO Labs, Carlsbad, CA). Polymerase chain reaction amplification of Pythium sp. DNA was conducted using the primer set internal transcribed spacer (ITS) 4 and ITS5 (32) in a GeneAmp 9700 thermal cycler (Applied Biosystems, Foster City, CA) using conditions previously described (30). Amplification products were confirmed by visual comparison to a 100-bp ladder following electrophoresis on a $1.5 \%$ agarose gel stained with ethidium bromide.

The resulting amplicon for each $P y$ thium isolate was digested with the restriction enzymes HinfI and HhaI in a single reaction mixture per the manufacture's protocol (New England BioLabs, Ipswich, MA). Fragments were separated on a $1.5 \%$ agarose gel in Tris-borate-EDTA buffer, stained with ethidium bromide, and DNA fragments were viewed using a UV transilluminator. Species identity was determined by comparison of the resulting restriction fragment length polymorphism (RFLP) patterns to those generated for a library of known Pythium spp. $(19,20)$. For three isolates representing a species-specific RFLP pattern, and instances where the resulting fragment pattern did not correspond to any previously defined species, the ITS4/ITS5 fragment was sequenced. Amplicons were cloned into the vector pCR4-TOPO (Invitrogen, Carlsbad, CA) and sequenced using a Dye Terminator Cycle Sequencing Quick Start Kit and a CEQ 8000 Genetic Analysis System capillary-based DNA sequencer (Beckman Coulter, Fullerton, CA). Sequencing was conducted in one direction employing M13 reverse (5'-CAGGAAACAGCTATGAC$\left.3^{\prime}\right)$ as the primer, consistently yielding 600 to $650 \mathrm{bp}$ reads. Identity of each sample was attained by comparing resulting DNA sequences to a local database collection and to GenBank (BLAST search).

Effect of AITC on growth of Pythium spp. The relative effect of exposure to AITC on subsequent growth of $P$. attrantheridium, $P$. irregulare, and $P$. heterothallicum was determined. GC soil was amended with B. juncea SM, and $250 \mathrm{~g}$ of 
soil was placed in a 0.946 -liter mason jar, with three replicate sample jars for each Pythium species. Pythium isolates were cultured on $1 / 5$ th-strength potato dextrose agar (PDA) in 60-mm-diameter petri plates. Lids were removed from plates, and for each sample jar a single inverted plate was placed within the jar suspended on wire mesh and sealed. Emission of AITC from $B$. juncea SM amended soil was determined as previously described (20). Cultures were incubated in sealed jars for $6 \mathrm{~h}$, at which time a $0.5-\mathrm{cm}$ agar disk was excised and placed on fresh PDA in 9.5$\mathrm{cm}$-diameter petri plates, with three replicate disks per sample. Individual samples were paired with cultures of the same species that had not been exposed to AITC, and all plates were incubated for $72 \mathrm{~h}$ at $24^{\circ} \mathrm{C}$. Linear hyphal growth from agar plugs exposed and unexposed to AITC was measured at 24,48 , and $72 \mathrm{~h}$.

Data analysis. Data were analyzed using SigmaStat (version 3.1; Systat Software Inc., Point Richmond, CA). Percent Pythium root infection data and soil population data were transformed to arcsinesquare root and $\log _{10}$ values, respectively, prior to conducting analysis of variance, and means separation was performed using the Student-Newman-Keuls method. Plant assays were conducted three times in GC

Table 1. Effect of rootstock, soil amendment, and their interactions on Pratylenchus penetrans infestation and Pythium infection of apple roots in assays conducted in GC orchard soil

\begin{tabular}{lcclcc}
\hline & \multicolumn{2}{c}{$\boldsymbol{P}$ penetrans root populations } & & \multicolumn{2}{c}{ Pythium root infection } \\
\cline { 2 - 3 } \cline { 5 - 6 } Source & $\boldsymbol{F}$ & $\boldsymbol{P}>\boldsymbol{F}$ & & $\boldsymbol{F}$ & $\boldsymbol{P}>\boldsymbol{F}$ \\
\hline Rootstock & 4.24 & $<0.001$ & & 30.53 & $<0.001$ \\
Soil treatment & 59.45 & $<0.001$ & & 194.25 & $<0.001$ \\
$\mathrm{R} \times \mathrm{S}$ & 5.39 & $<0.001$ & & 11.36 & $<0.001$ \\
\hline
\end{tabular}

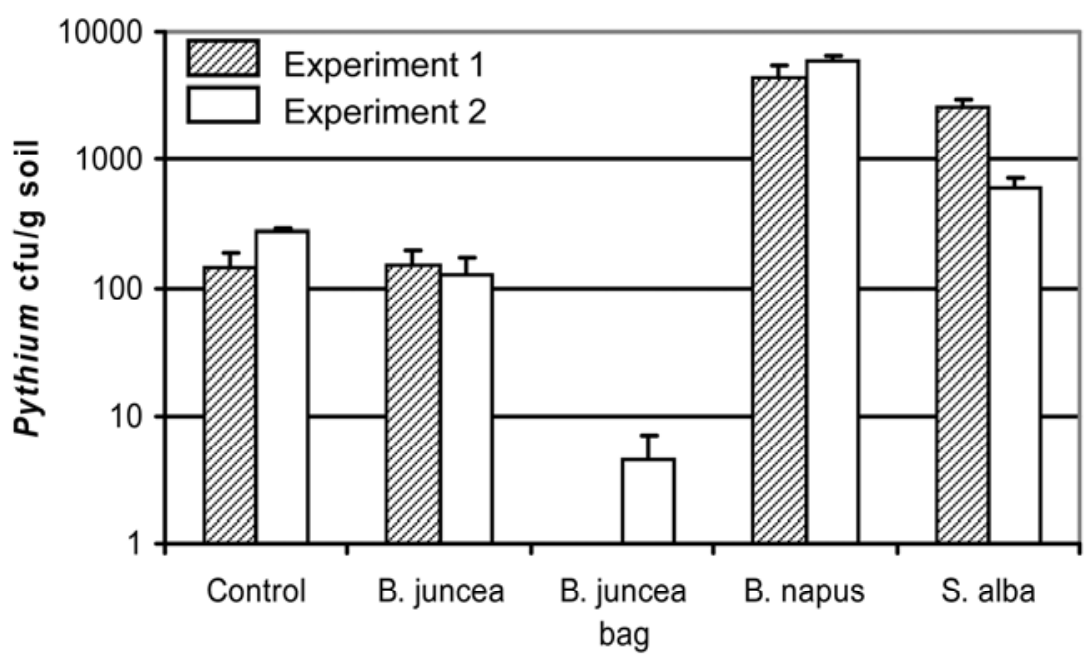

\section{Soil treatment}

Fig. 1. Effect of seed meal amendments on recovery of Pythium spp. from GC orchard soils immediately prior to planting. Values consist of data from all pots with $n=44$. Bars represent standard error of the mean. orchard soil and one time in WVC orchard soil. Studies were not repeated in soil from the WVC site due to removal of the orchard.

\section{RESULTS}

Effect of seed meal and rootstock on Pythium root infection. Seed meal amendment and rootstock had significant impact on apple root infection by resident Pythium populations (Table 1). Relative to the nontreated control, GC soils amended with $B$. napus SM exhibited a significant $(P<0.001)$ increase in Pythium populations, from approximately $150 \mathrm{CFU} \mathrm{\textrm {g } ^ { - 1 }}$ soil to $4,400 \mathrm{CFU} \mathrm{g}{ }^{-1}$ soil or greater at planting (Fig. 1). GC soil treated with $S$. alba SM exhibited a similar response in experiment 1 , and a significant but less substantial increase in experiment 2 (Fig. 1). In contrast, application of B. juncea SM did not significantly elevate Pythium numbers recovered from orchard soil, and when soils were contained in sealed polyethylene bags for a period of $48 \mathrm{~h}$ immediately post-SM amendment, Pythium numbers were significantly $(P=0.002)$ reduced relative to the nontreated control. At harvest, relative soil populations among treatments remained stable, but total populations for a given treatment exhibited a decline (data not shown). The Pythium population resident to WVC soil was less responsive to seed meal amendments. Only B. napus $\mathrm{SM}$ amendment significantly $(P<$ 0.001) elevated populations of Pythium relative to the nontreated control, with numbers increasing from $274 \mathrm{CFU} \mathrm{g}^{-1}$ to 1,045 CFU g ${ }^{-1}$ (Table 2). In a separate trial, bagging of $B$. napus-treated GC soil did not alter the response in Pythium numbers. Soil populations of Pythium increased from $125 \mathrm{CFU} \mathrm{g}^{-1}$ to 1,633 and 1,475 CFU $\mathrm{g}^{-1}$ when soils were incubated for $96 \mathrm{~h}$ in the open or in sealed bags, respectively.

Similar patterns to those detected in soil were observed in recovery of Pythium from roots of apple grown in orchard soils. Pythium apple root infection was significantly $(P<0.001)$ elevated for trees grown in B. napus SM and S. alba SM amended

Table 2. Effect of seed meal type on size and percent species composition of Pythium spp. populations recovered from soil and roots of apple, respectively, in WVC and GC orchard soils

\begin{tabular}{|c|c|c|c|c|c|c|c|}
\hline \multirow{2}{*}{$\begin{array}{l}\text { Soil treatment } \\
\text { WVC orchard }\end{array}$} & \multirow{2}{*}{$\begin{array}{c}\text { Pythium } \\
\text { CFU g-1 soil }\end{array}$} & \multicolumn{6}{|c|}{ Pythium species } \\
\hline & & P. att. $^{\mathrm{y}}$ & P. het. & P. irr. & P. ros. & P. ult. ult. & P. vex. \\
\hline Control & $274 \mathrm{a}^{\mathrm{z}}$ & $10.3 \mathrm{a}$ & $51.5 \mathrm{a}$ & $10.3 \mathrm{a}$ & $3.4 \mathrm{a}$ & $0 \mathrm{a}$ & $24.1 \mathrm{~b}$ \\
\hline Brassica juncea & $127 \mathrm{a}$ & $0 \mathrm{a}$ & $42.9 \mathrm{a}$ & $34.2 \mathrm{~b}$ & $2.9 \mathrm{a}$ & $8.6 \mathrm{a}$ & $11.4 \mathrm{ab}$ \\
\hline B. napus & $1,045 \mathrm{~b}$ & $0 \mathrm{a}$ & $84.9 \mathrm{~b}$ & $0 \mathrm{a}$ & $0 \mathrm{a}$ & $13.2 \mathrm{a}$ & $1.9 \mathrm{a}$ \\
\hline Sinapis alba & $600 a b$ & $0 \mathrm{a}$ & $42.1 \mathrm{a}$ & $26.3 \mathrm{ab}$ & $0 \mathrm{a}$ & $31.6 \mathrm{~b}$ & $0 \mathrm{a}$ \\
\hline GC orchard & & P. att. & P. deb. & P. het. & P. irr. & P. ros. & P. syl. \\
\hline Control & $145 \mathrm{a}$ & $40.0 \mathrm{~b}$ & $10.0 \mathrm{a}$ & $17.5 \mathrm{a}$ & $15.0 \mathrm{a}$ & $0 \mathrm{a}$ & $17.5 \mathrm{~b}$ \\
\hline B. juncea & $154 \mathrm{a}$ & $5.9 \mathrm{a}$ & $9.8 \mathrm{a}$ & $11.8 \mathrm{a}$ & $68.6 \mathrm{~b}$ & $0 \mathrm{a}$ & $3.9 \mathrm{a}$ \\
\hline B. napus & $4,486 \mathrm{c}$ & $29.7 \mathrm{ab}$ & $5.8 \mathrm{a}$ & $46.6 \mathrm{~b}$ & $15.5 \mathrm{a}$ & $1.4 \mathrm{a}$ & $1.0 \mathrm{a}$ \\
\hline S. alba & $2,563 \mathrm{~b}$ & $24.2 \mathrm{ab}$ & $35.6 \mathrm{~b}$ & $21.2 \mathrm{a}$ & $12.9 \mathrm{a}$ & $0 \mathrm{a}$ & $6.1 \mathrm{a}$ \\
\hline
\end{tabular}

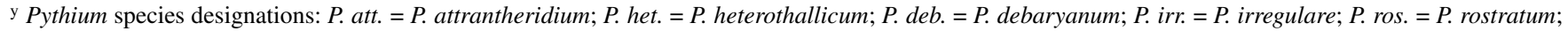

P. ult. ult. $=P$. ultimum var. ultimum $;$. vex. $=P$. vexans $;$. syl. $=P$. sylvaticum .

${ }^{\mathrm{z}}$ Means in the same column followed by the same letter are not significantly different based upon the Student-Newman-Keuls test. 


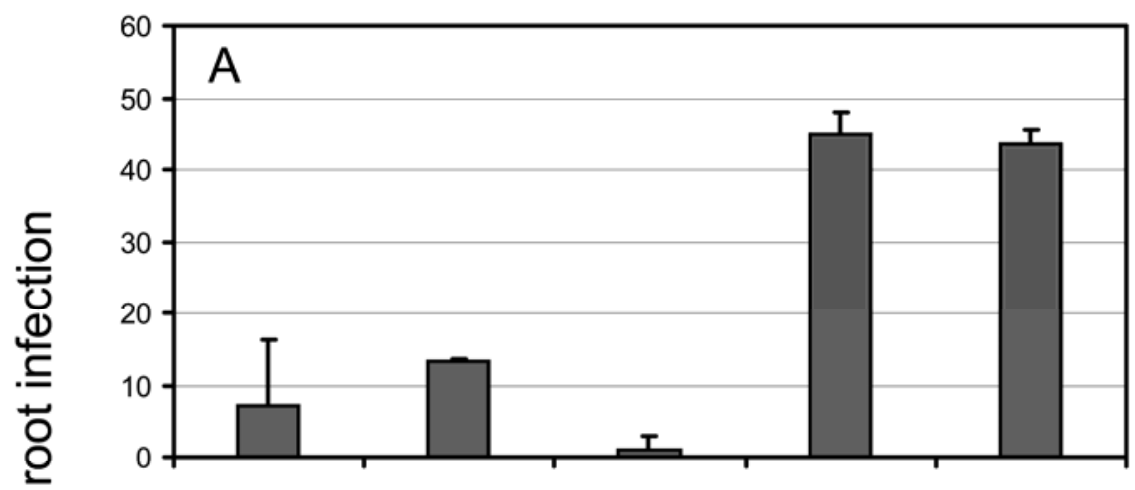

GC soils (Fig. 2A). Pythium root infection was lowest in $B$. juncea SM-bagged GC soil, although not significantly $(P=0.454)$ different from the control. Trees grown in $B$. juncea SM amended GC soil had significantly $(P=0.011)$ higher Pythium spp. infection frequencies than trees grown in B. juncea SM-bagged GC soil. Relative to GC soil, Pythium spp. infection of apple roots grown in WVC soils was lower, and only trees established in B. napus SM amended soil exhibited infection levels significantly $(P<0.001)$ higher than the nontreated control (Fig. 2B).

Recovery of Pythium spp. from apple roots also displayed a rootstock-dependent pattern. In assays conducted in GC soil, when evaluated across all soil treatments, M26, MM106, and MM111 demonstrated significantly $(P<0.05)$ higher levels of Pythium spp. root infection relative to all other rootstocks employed in this study (Fig. 3). These differences clearly stemmed from the higher rates of Pythium spp. root infection realized for these rootstocks in B. napus and $S$. alba SM amended soil, as no significant differences were observed in infection rates among rootstocks when grown in control or $B$. juncea SM treated soils. There were no significant differences in Pythium root infection rates among apple rootstocks grown in WVC orchard soil (data not shown).

Effect of seed meal on composition of

Fig. 2. Effect of soil treatments on percent infection of apple roots by populations of Pythium spp. native to $\mathbf{A}, \mathrm{GC}$ and $\mathbf{B}, \mathrm{WVC}$ orchard soils. Values for a given soil treatment represent average percent root infection across all apple rootstocks, with $n=44$. Bars represent standard error of the mean.
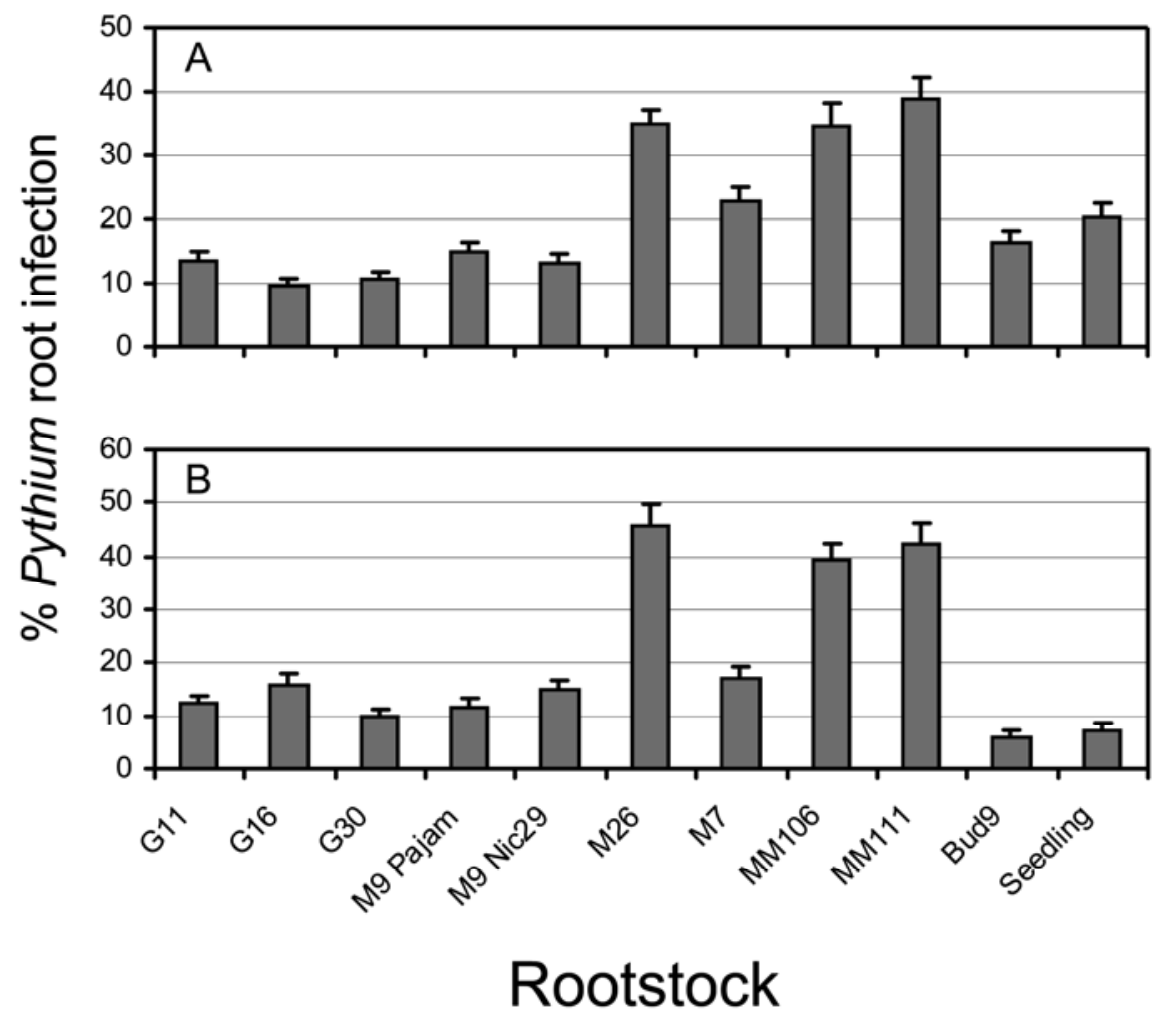

Fig. 3. Effect of rootstock on apple root infection (\%) by populations of Pythium native to nontreated (control) GC orchard soil. Bars indicate standard error of the mean. A, experiment 1, and $\mathbf{B}$, experiment 2. only differed in their capacity to suppress Pythium soil populations and root infection, but also differentially transformed composition of the population recovered from apple roots, although in a soilspecific manner. The Pythium populations recovered from roots of apple grown in nontreated WVC and GC orchard soil were composed of six different species, with $P$. heterothallicum and $P$. attrantheridium representing the largest proportion in the respective soils. The population that persisted in roots of apple grown in GC soil post- $B$. juncea SM amendment was dominated by $P$. irregulare, comprising $68.6 \%$ of isolates (Table 2). A similar, although less apparent response was observed in the population recovered from roots of trees grown in WVC orchard soil: P. irregulare increased from $10.3 \%$ in the control to approximately $34.2 \%$ in the B. juncea SM treatment (Table 2). Amendment of soils with $S$. alba SM tended to result in a more uniform distribution of individuals among species with no species clearly dominant. P. ultimum var. ultimum, a species that was not isolated from apple roots grown in nontreated soil, was recovered from apple grown in all WVC seed meal amended soils. This species comprised nearly a third of the isolates recovered from roots of apple planted in $S$. alba SM amended WVC orchard soil. The Pythium population recovered from roots of apple estab- 
lished in B. napus SM amended WVC soil was predominantly $(84.9 \%)$ composed of $P$. heterothallicum, and the proportion of this species recovered from trees grown in B. napus SM amended GC orchard soil was higher than in the control.

Relative sensitivity of Pythium spp. to AITC. Peak AITC emission from $B$. juncea SM treated soil was recorded within $3 \mathrm{~h}$ post-seed meal amendment (data not shown). Exposure to AITC suppressed the initial growth of $P$. heterothallicum on $1 / 5$ th-strength PDA, and its relative growth was significantly $(P<0.001)$ lower than that observed for $P$. attrantheridium and P. irregulare (Fig. 4). Thereafter, $P$. heterothallicum growth was observed, but at $72 \mathrm{~h}$ its relative growth was still the lowest among the three species examined. At the final sampling time, relative growth of $P$. irregulare was significantly $(P=$ $0.028)$ greater than $P$. attrantheridium.

Effect of seed meal and rootstock on recovery of Pratylenchus penetrans. Root populations of $P$. penetrans were significantly lower on apple rootstocks planted in brassicaceous seed meal amended GC orchard soil. Across apple rootstocks, $B$. juncea SM was more effective than either B. napus SM or S. alba SM in suppressing $P$. penetrans root populations (Fig. 5). Among the apple rootstocks used in this study, lower numbers of $P$. penetrans were consistently recovered from G11 and G30 rootstocks grown in nontreated GC orchard soil (Table 3). In general, Malling series rootstocks supported higher lesion nematode numbers; however, relative root populations of $P$. penetrans were not consistent among certain apple rootstocks. For example, M9 rootstock supported significantly lower lesion nematode populations relative to M7, MM106, and MM111 in experiment 3 , but among these rootstocks there were no significant differences in populations recovered in experiment 2 . Furthermore, in experiment 1 , the highest lesion nematode numbers were recovered from M9 NIC29 rootstock.

Significant $(P<0.001)$ rootstock $\times$ seed meal interactions were observed in the suppression of lesion nematode populations. In general, B. napus and $S$. alba seed meals did not significantly reduce lesion nematode populations on more susceptible apple rootstocks such as M7, M26, MM106, and MM111 (Table 4). In contrast, significant reductions in lesion nematode root populations were observed in response to $B$. juncea SM irrespective of apple rootstock, and all seed meal amendments significantly reduced lesion nematode populations recovered from roots of G11 and G30 in all experiments.

\section{DISCUSSION}

Although rootstock tolerance to apple replant disease has been reported (12), the commercial viability of this approach has yet to be validated since rootstock disease tolerance is typically made based upon growth performance rather than examination of resistance or tolerance to the causal pathogen complex. As the disease is caused by a diversity of pathogens, often consisting of multiple species within a given genus, such assessments may not be valid across orchard systems.
Similarly, although brassicaceous seed meal amendments have been promoted for use in the control of soilborne diseases, the efficacy of such an approach in the control of replant disease has exhibited significant variability across orchard sites, disease control or lack thereof, directly linked to composition of the patho-

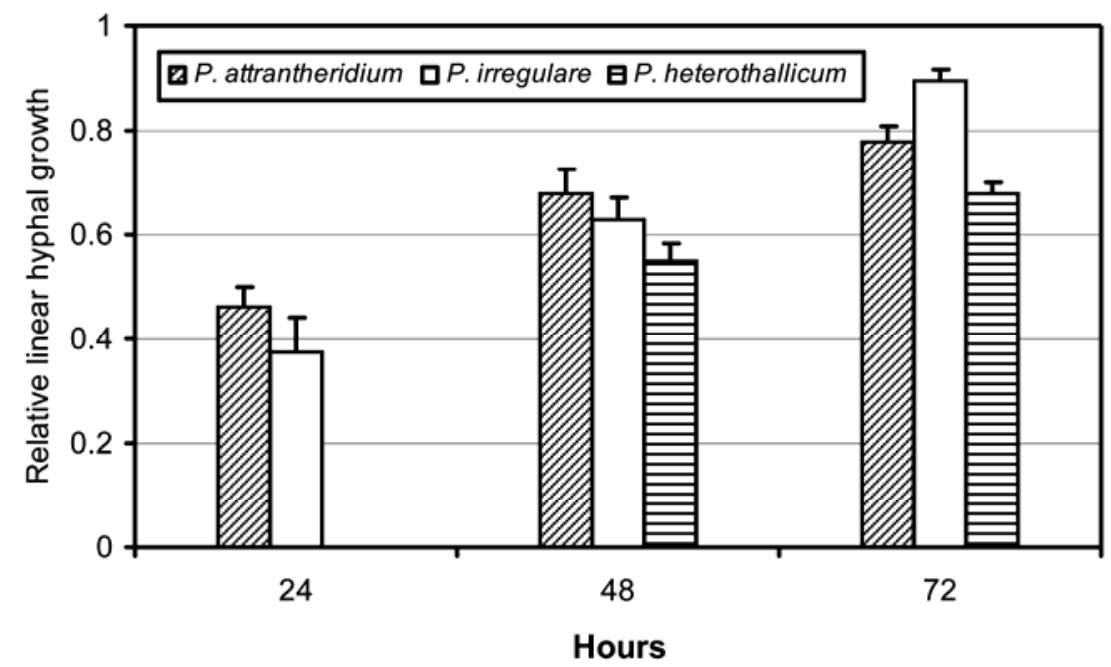

Fig. 4. Relative linear growth of Pythium after a 6-h exposure period in enclosed jars to allylisothiocyanate generated via the incorporation of Brassica juncea seed meal into GC orchard soil. Bars indicate standard error of the mean.

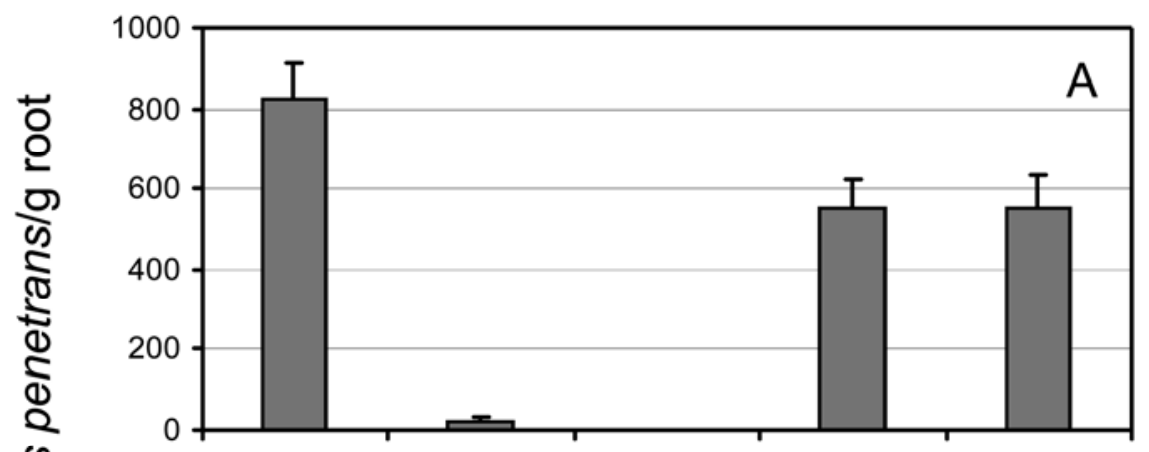

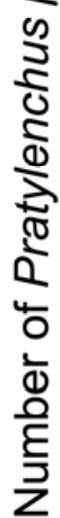

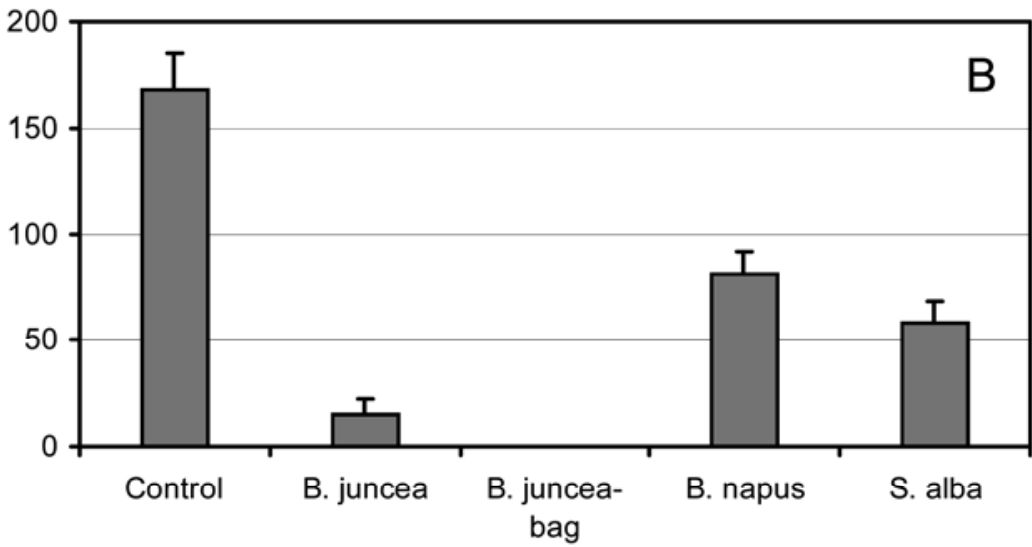

Soil treatment

Fig. 5. Effect of brassicaceous seed meal amendments on recovery of Pratylenchus penetrans from roots of apple rootstocks grown in GC orchard soil. Values consist of data from all rootstocks with $n=$ 44. Bars represent standard error of the mean. A, experiment 1 , and $\mathbf{B}$, experiment 2. 
gen complex resident to a particular site (22).

In this study, apple root infestation by two elements of the pathogen complex that incites replant disease was affected by both rootstock genotype and seed meal plant source. Similar to a previous report (12), differential tolerance to lesion nematode was observed among apple rootstocks, with G11 and G30 rootstocks generally supporting lower populations than Malling or Malling-Merton rootstocks in this study. All brassicaceous seed meals utilized in this study suppress lesion nematode populations, but among these B. juncea SM has consistently provided superior nematode suppression in assays that employed Gala apple seedlings (19). Similar results were observed in the current study that utilized apple rootstocks, but a significant interaction between rootstock and seed meal type was observed. When utilized with rootstocks such as G11 or G30, which inherently supported lower lesion nematode numbers, all seed meals significantly suppressed $P$. penetrans root populations. In contrast, although $B$. juncea SM provided effective nematode suppression irrespective of rootstock, in general, B. napus and $S$. alba seed meals were less effective or ineffective in suppressing $P$. penetrans root populations when used in concert with a highly susceptible rootstock such as M26 or MM111. This response is likely a function of multiple factors including seed meal mode of action in nematode suppres- sion and fecundity of $P$. penetrans on the individual rootstocks. $B$. juncea SMinduced nematode suppression functions in part through the nematicidal activity of AITC $(23,35)$, which is generated in response to hydrolysis of 2-propenylglucosinolate. In contrast, ITCs produced by $B$. napus SM and $S$. alba SM have lower or lack nematicidal activity $(14,23)$, and nematode suppression realized in response to these and other high $\mathrm{N}$ containing seed meals, such as soybean meal (8), likely functions predominantly through the liberation of ammonia $(24,26,29)$. The reported transitory suppression of $P$. penetrans in response to $B$. napus SM or $S$. alba SM $(20,22)$ suggests that their effect was nematistatic rather than nematicidal, so that as nitrification progresses, inhibitory activity of ammonia released from these seed meals $(24,26)$ is lost and nematode populations recover in the presence of the more susceptible rootstocks. This is supported by the observation that the use of a nitrification inhibitor enhanced the nematode suppressive capacity of ammonia-releasing compounds (24).

As reported previously (20), brassicaceous seed meal amendments differentially influenced population densities of Pythium resident to orchard soils. B. napus and $S$. alba SM consistently amplified Pythium populations, while $B$. juncea SM did not significantly alter density of this oomycete population relative to the nontreated control soil. Bagging B. juncea SM amended

Table 3. Pratylenchus penetrans populations recovered from the roots of apple rootstocks grown in nontreated (control) soil from the GC orchard, Orondo, WA

\begin{tabular}{lccc}
\hline & \multicolumn{3}{c}{ P. penetrans $\mathbf{g}^{-1}$ of soil } \\
\cline { 2 - 4 } Apple rootstock & Exp1 & Exp2 & Exp3 \\
\hline Bud9 & $578 \mathrm{a}^{\mathrm{z}}$ & $271 \mathrm{~b}$ & $142 \mathrm{a}$ \\
G11 & $434 \mathrm{a}$ & $44 \mathrm{a}$ & $\ldots$ \\
G16 & $1,269 \mathrm{bc}$ & $168 \mathrm{ab}$ & $195 \mathrm{a}$ \\
G30 & $471 \mathrm{a}$ & $80 \mathrm{a}$ & $\ldots$ \\
M7 & $930 \mathrm{ab}$ & $141 \mathrm{ab}$ & $710 \mathrm{~b}$ \\
M9 Pajam2 & $673 \mathrm{a}$ & $243 \mathrm{~b}$ & $254 \mathrm{a}$ \\
M9 Nic29 & $1,557 \mathrm{c}$ & $250 \mathrm{~b}$ & $284 \mathrm{a}$ \\
M26 & $954 \mathrm{ab}$ & $164 \mathrm{ab}$ & $480 \mathrm{ab}$ \\
MM106 & $499 \mathrm{a}$ & $154 \mathrm{ab}$ & $1,758 \mathrm{c}$ \\
MM111 & $1,084 \mathrm{~b}$ & $260 \mathrm{~b}$ & $851 \mathrm{~b}$ \\
Seedling & $956 \mathrm{ab}$ & $88 \mathrm{a}$ & $371 \mathrm{a}$ \\
$P=$ & 0.003 & 0.021 & $<0.001$ \\
\hline
\end{tabular}

${ }^{\mathrm{z}}$ Means in a column followed by the same letter are not significantly $(P>0.05)$ different. soil for a 48-h period post-seed meal amendment significantly reduced Pythium populations and subsequent apple root infection. Conversely, treating $B$. napus SM soils in this manner did not alter the observed response in Pythium populations. This finding suggests that a mechanism such as anaerobiosis (1) is not responsible for the B. juncea induced suppression of Pythium in sealed bags but rather it resulted from enhanced concentration and retention of AITC in treated soil. This finding suggests that, as is the case for other volatile chemistries such as methyl bromide or methyl iodide, tarping soil with a plastic film after B. juncea SM soil incorporation may enhance treatment efficacy under field conditions. Such an outcome was observed in terms of weed control and suppression of Pythium populations in field trials that employed tarping of B. juncea SM treated soils (11).

Certain conventionally managed replant orchard soils that have been the focal point of our studies on replant disease have yielded relatively low rates of root infection by native Pythium spp. populations (17). At the GC orchard, this may be explained in part by the low organic matter content and well drained nature of this coarse textured soil. However, in these same soils, the addition of an organic amendment elicits a rapid and precipitous increase in Pythium soil populations. Differential susceptibility among apple rootstocks was only detected when assessments were conducted in orchard soils amended with B. napus SM or S. alba SM, both of which elevated resident Pythium spp. populations. Similar to $P$. penetrans, under these experimental conditions, significant rootstock $\times$ seed meal interactions were observed in relation to Pythium root infection. In general, M26, MM106, and MM111 rootstocks were more susceptible to the native populations of Pythium spp. resident to these orchard soils than Geneva series or Bud9 rootstock.

Pythium populations recovered from roots of apple grown in nontreated WVC and GC orchard soils were dominated by $P$. heterothallicum and $P$. attrantheridium, respectively. Both species remained significant components of the Pythium population recovered from roots of apple grown

Table 4. Effect of apple rootstock genotype on brassicaceous seed meal-induced suppression of Pratylenchus penetrans root populations recovered from selected apple rootstocks grown in GC orchard soil

\begin{tabular}{|c|c|c|c|c|c|c|c|c|c|c|c|c|}
\hline \multirow[b]{3}{*}{ Soil treatment } & \multicolumn{12}{|c|}{ Apple rootstock } \\
\hline & \multicolumn{2}{|c|}{ G11 } & \multicolumn{2}{|c|}{ G30 } & \multicolumn{2}{|c|}{ M7 } & \multicolumn{2}{|c|}{ M26 } & \multicolumn{2}{|c|}{ MM106 } & \multicolumn{2}{|c|}{ MM111 } \\
\hline & Exp1 & Exp2 & Exp1 & Exp2 & Exp1 & Exp2 & Exp1 & Exp2 & Exp1 & Exp2 & Exp1 & $\operatorname{Exp2}$ \\
\hline$\overline{\text { Control }}$ & $434 b^{y}$ & $44 \mathrm{~b}$ & $471 \mathrm{c}$ & $80 \mathrm{~b}$ & $930 \mathrm{~b}$ & $141 \mathrm{~b}$ & $954 \mathrm{c}$ & $164 \mathrm{~b}$ & $499 \mathrm{~b}$ & $154 \mathrm{~b}$ & $1,084 \mathrm{c}$ & $260 \mathrm{~b}$ \\
\hline Brassica juncea & $6 \mathrm{a}$ & $0 \mathrm{a}$ & $1 \mathrm{a}$ & $1 \mathrm{a}$ & $5 \mathrm{a}$ & $17 \mathrm{a}$ & $11 \mathrm{a}$ & $1 \mathrm{a}$ & $32 \mathrm{a}$ & $9 \mathrm{a}$ & $2 \mathrm{a}$ & $8 \mathrm{a}$ \\
\hline B. juncea-bag ${ }^{\mathrm{z}}$ & $0 \mathrm{a}$ & $0 \mathrm{a}$ & $0 \mathrm{a}$ & $0 \mathrm{a}$ & $1 \mathrm{a}$ & $0 \mathrm{a}$ & $0 \mathrm{a}$ & $0 \mathrm{a}$ & $1 \mathrm{a}$ & $0 \mathrm{a}$ & $0 \mathrm{a}$ & $0 \mathrm{a}$ \\
\hline B. napus & $101 \mathrm{a}$ & $6 a$ & $138 \mathrm{~b}$ & $20 \mathrm{a}$ & $884 \mathrm{~b}$ & $149 \mathrm{~b}$ & $1,588 \mathrm{~d}$ & $68 \mathrm{ab}$ & $456 \mathrm{~b}$ & $212 b$ & $738 \mathrm{~b}$ & $89 a b$ \\
\hline Sinapis alba & $108 \mathrm{a}$ & $7 \mathrm{a}$ & $153 \mathrm{~b}$ & $14 \mathrm{a}$ & $638 \mathrm{~b}$ & $158 \mathrm{~b}$ & $429 \mathrm{~b}$ & $150 \mathrm{~b}$ & $1,642 \mathrm{c}$ & $170 \mathrm{~b}$ & $1,053 \mathrm{c}$ & $26 \mathrm{a}$ \\
\hline
\end{tabular}

${ }^{\mathrm{y}}$ Means in a column followed by the same letter are not significantly $(P>0.05)$ different.

${ }^{\mathrm{z}} B$. juncea seed meal amended soil sealed within a polyethylene bag for a 48 -h period immediately following soil treatment. 
in B. napus $\mathrm{SM}$ amended soils, but this was not necessarily the case in $B$. juncea or $S$. alba SM amended soil. In GC soil, $B$. juncea $\mathrm{SM}$ amendment transformed the population to one dominated by $P$. irregulare, a species that exhibits a higher level of virulence toward apple than $P$. attrantheridium (19). Ultimate Pythium population composition in $B$. juncea SM amended soil did not appear to be directly associated with relative sensitivity to AITC, at least initially, as relative growth rates of $P$. attrantheridium and $P$. irregulare exposed to AITC were similar. Overall, this may be insignificant with regard to tree performance due to the low levels of apple root infection detected in $B$. juncea $\mathrm{SM}$ treated soils. Of potentially greater concern is the alteration in the Pythium population recovered from roots of apple grown in WVC orchard soil in response to S. alba SM. P. ultimum var. ultimum was not recovered from trees grown in nontreated WVC orchard soil but represented nearly $1 / 3$ of the isolates recovered from trees grown in $S$. alba SM amended soil. Within the diverse complex of $P y$ thium associated with apple, $P$. ultimum var. ultimum is consistently among the most virulent toward apple (19). Together with the increased infection frequency resulting from $S$. alba SM amendment, such a treatment has the potential to intensify tree damage resulting from native orchard soil Pythium populations.

Replant disease of apple is caused by a consortium of soilborne pathogens that includes various species of Pythium and $P$. penetrans $(2,10,13,17,28)$. Commercially acceptable control of this disease has continued to rely upon use of preplant soil fumigation. Such an approach is not compatible with organic production systems, and alternative practices for replant disease control are needed for this expanding component of the tree fruit industry. Soil amendments and host resistance are commonly employed strategies used for the management of soilborne diseases in organic production systems. Effective application of either approach individually for control of such a biologically complex disease syndrome seems improbable. The results of this study suggest that certain brassicaceous amendments may actually exacerbate disease severity. However, our findings also indicate that a systematic integration of an appropriate brassicaceous seed meal amendment in concert with rootstock resistance/tolerance may provide a more effective strategy for the management of apple replant disease.

\section{LITERATURE CITED}

1. Blok, W. J., Lamers, J. G., Termorshuizen, A. J., and Bollen, G. J. 2000. Control of soilborne plant pathogens by incorporating fresh organic amendments followed by tarping. Phytopathology 90:253-259.

2. Braun, P. G. 1995. Effects of Cylindrocarpon and Pythium species on apple seedlings and potential role in apple replant disease. Can. J. Plant Pathol. 17:336-341.

3. Brown, J., Davis, J. B., Erickson, D. A., Brown, A. P., and Seip, L. 1997. Registration of 'IdaGold' mustard. Crop Sci. 38:541.

4. Brown, J., Davis, J. B., Erickson, D. A., Seip, L., and Gosselin, T. 2004. Registration of 'Pacific Gold' condiment yellow mustard. Crop Sci. 44:2271-2272.

5. Browne, G. T., and Mircetich, S. M. 1993. Relative resistance of thirteen apple rootstocks to three species of Phytophthora. Phytopathology 83:744-749.

6. Browne, G. T., Mircetich, S. M., and Cummins, J. N. 1995. Relative resistance of eighteen selections of Malus spp. to three species of Phytophthora. Phytopathology 85:72-76.

7. Cohen, M. F., and Mazzola, M. 2006. Impact of resident bacteria, nitric oxide emission and particle size on root infection by Pythium spp. and $R$. solani AG-5 in Brassica napus seed meal amended soils. Plant Soil 286:75-86.

8. Cohen, M. F., Yamasaki, H., and Mazzola, M. 2005. Brassica napus seed meal soil amendment modifies microbial community structure, nitric oxide production and incidence of Rhizoctonia root rot. Soil Biol. Biochem. 37:1215-1227.

9. Covey, R. P., Jr., Benson, N. R., and Haglund, W. A. 1979. Effects of soil fumigation on the apple replant disease in Washington. Phytopathology 69:684-686.

10. Dullahide, S. R., Stirling, G. R., Nikulin, A., and Stirling, A. M. 1994. The role of nematodes, fungi, bacteria, and abiotic factors in the etiology of apple replant problems in the Granite Belt of Queensland. Aust. J. Exp. Agric. 34:1177-1182.

11. Hoagland, L., Carpenter-Boggs, L., Reganold, J., and Mazzola, M. 2008. Role of native soil biology in brassicaceae seed meal induced weed suppression. Soil Biol. Biochem. 40:1689-1697.

12. Isutsa, D. K., and Merwin, I. A. 2000. Malus germplasm varies in resistance or tolerance to apple replant disease in a mixture of New York orchard soils. HortScience 35:262-268.

13. Jaffee, B. A., Abawi, G. S., and Mai, W. F. 1982. Role of soil microflora and Pratylenchus penetrans in an apple replant disease. Phytopathology 72:247-251.

14. Lazzeri, L., Tacconi, R., and Palmieri, S. 1993. In vitro activity of some glucosinolates and their reaction products toward a population of the nematode Heterodera schachtii. J. Agric. Food Chem. 41:825-829.

15. Mai, W. F., and Abawi, G. S. 1981. Controlling replant diseases of pome and stone fruits in northeastern United States by preplant fumigation. Plant Dis. 65:859-864.

16. Mazzola, M. 1997. Identification and pathogenicity of Rhizoctonia spp. isolated from apple roots and orchard soil. Phytopathology 87:582-587.

17. Mazzola, M. 1998. Elucidation of the microbial complex having a causal role in the development of apple replant disease in Washington. Phytopathology 88:930-938.

18. Mazzola, M. 1999. Transformation of soil microbial community structure and Rhizoctonia-suppressive potential in response to apple roots. Phytopathology 89:920-927.

19. Mazzola, M., Andrews, P. K., Reganold, J. P., and Lévesque, C. A. 2002. Frequency, virulence, and metalaxyl sensitivity of Pythium spp. isolated from apple roots under conventional and organic production systems. Plant Dis. 86:669-675.

20. Mazzola, M., Brown, J., Izzo, A. D., and Cohen, M. F. 2007. Mechanism of action and efficacy of seed meal-induced pathogen suppression differ in a Brassicaceae species and time-dependent manner. Phytopathology 97:454-460.

21. Mazzola, M., Granatstein, D. M., Elfving, D. C., and Mullinix, K. 2001. Suppression of specific apple root pathogens by Brassica napus seed meal amendment regardless of glucosinolate content. Phytopathology 91:673-679.

22. Mazzola, M., and Mullinix, K. 2005. Comparative field efficacy of management strategies containing Brassica napus seed meal or green manure for the control of apple replant disease. Plant Dis. 89:1207-1213.

23. Mojtahedi, H., and Santo, G. S. 1996. Toxicity of isothiocyanate derivatives to Meloidogyne chitwoodi and Pratylenchus penetrans in soil environment. Pages 128-129 in: Proc. 3rd Int. Nematol. Congr., Guadaloup, Mexico.

24. Oka, Y., and Pivonia, S. 2003. Effect of a nitrification inhibitor on nematicidal activity of organic and inorganic ammonia-releasing compounds against the root-knot nematode Meloidogyne javanica. Nematology 5:505-513.

25. Patrick, Z. A. 1955. The peach replant problem in Ontario. II. Toxic substances from microbial decomposition products of peach root residues. Can. J. Bot. 33:461-486.

26. Rodríguez-Kabana, R. 1986. Organic and inorganic nitrogen amendments to soil as nematode suppressants. J. Nematol. 18:129 135.

27. Rumberger, A., Yao, S., Merwin, I. A., Nelson, E. B., and Thies, J. E. 2004. Rootstock genotype and orchard replant position rather than soil fumigation or compost amendment determine tree growth and rhizosphere bacterial community composition in an apple replant soil. Plant Soil 264:246-260.

28. Sewell, G. W. F. 1981. Effects of Pythium species on the growth of apple and their possible causal role in apple replant disease. Ann Appl. Biol. 97:149-169.

29. Stirling, G. R. 1991. Biological Control of Plant Parasitic Nematodes. CAB International, Wallingford, UK

30. Tewoldemedhin, Y. T., Lamprecht, S. C., McLeod, A., and Mazzola, M. 2006. Characterization of Rhizoctonia spp. recovered from crop plants used in rotational cropping systems in the Western Cape Province of South Africa. Plant Dis. 90:1399-1406.

31. Traquair, J. A. 1984. Etiology and control of orchard replant problems: A review. Can. J. Plant Pathol. 6:54-62.

32. White, T. J., Bruns, T., Lee, S., and Taylor, J. 1990. Amplification and direct sequencing of fungal ribosomal RNA genes for phylogenetics. Pages 315-324 in: PCR Protocols: A Guide to Methods and Applications. M. A. Innis, D. H. Gelfand, J. J. Sninsky, and T. J. White, eds. Academic Press, San Diego, CA.

33. Wilcox, W. F. 1993. Incidence and severity of crown and root rots on four apple rootstocks following exposure to Phytophthora species and waterlogging. J. Am. Soc. Hortic. Sci. 118:63-67.

34. Wood, B. W., Reilly, C. C., and Nyczepir, A. P. 2006. Field deficiency of nickel in trees: Symptoms and causes. Acta Hortic. 721:83-97.

35. Zasada, I. A., and Ferris, H. 2004. Nematode suppression with brassicaceous amendments: Application based upon glucosinolate profile. Soil Biol. Biochem. 36:1017-1024. 